\title{
Bone Defect Management with Vascularized Fibular Grafts in the Treatment of Grade III-IV Osteomyelitis
}

\author{
Management von Knochendefekten durch vaskularisierte \\ Fibula-Transplantate bei der Behandlung von Osteomyelitis \\ vom Grad III-IV
}

Authors

Andrea Antonini ${ }^{1}$, Carlo Rossello ${ }^{2}$, Carlo Salomone ${ }^{1}$, Paolo lacoviello ${ }^{3}$, Francesco Chiarlone ${ }^{1}$, Giorgio Burastero ${ }^{1}$

Institutes

1 ASL2 Savonese Malattie Infettive e Ortopedia Settica

2 Ospedale San Paolo Hand Surgery

3 Ente Ospedaliero Ospedali Galliera Chirurgia Maxillo-Facciale e Plastica Ricostruttiva

Schlüsselwörter

Fibula-Flap, freies Flap, Infektion, Pathologie, Peroneus-brevis-Flap

Key words

Osteomyelitis, fibula flap, free flap, peroneus brevis flap, infection

submitted 31.01.2019

accepted $\quad 06.04 .2019$

Bibliograpy

DOI https://doi.org/10.1055/a-0893-6718

Handchir Mikrochir Plast Chir 2019; 51: 444-452

(c) Georg Thieme Verlag KG Stuttgart · New York

ISSN 0722-1819

Correspondence Address

MD Andrea Antonini

ASL2 Savonese Malattie Infettive e Ortopedia Settica

Ospedale di Albenga

17031 Albenga

Tel.: 0182546024

Fax: 0182546354

E-Mail: aantoninimd@gmail.com

\section{ZUSAMMENFASSUNG}

Zielsetzung Bei dieser Studie handelt es sich um eine retrospektive Analyse unserer Erfahrungen mit mikrochirurgischen Knochentransfers für komplexe Rekonstruktionen von Gliedmaßen. Ziel der Studie war es, die Zuverlässigkeit der Technik der vaskularisierten Fibula-Transplantation zu beurteilen: Infektionsrezidive, Hypertrophie, Zeit bis zur knöchernen Durchbauung, Komplikationen und Zeit bis zur Heilung bei Patienten mit schwerer Osteomyelitis (Grad III und IV nach Cierny-Mader) über einen Nachbeobachtungszeitraum von 38 bis 93 Monaten.
Patienten und Methoden Von März 2010 bis Dezember 2015 wurden Gliedmaßen von 18 Patienten (6 Frauen und 12 Männer; mittleres Alter 48,7 Jahre) mit 10 freien Fibula-Flaps, 5 gestielten Fibula-Flaps und 3 osteomuskulären Peroneus-brevis-Flaps rekonstruiert. Wir rekonstruierten 2 Radien, 2 Ulnae, 4 Femora, 4 Tibiae, 1 Acetabulum und 3 laterale Malleoli.

Ergebnisse Ein Operationsergebnis wurde als erfolgreich gewertet, wenn der Patient eine erfolgreiche funktionelle Knochenrekonstruktion erreichte und während der Nachbeobachtung (mittlerer Zeitraum 63,6 Monate) keine erneute Infektion auftrat. Unsere Ergebnisse waren wie folgt: 14 vollständige funktionelle Rekonstruktionen, 2 Gliedmaßenrettungen mit eingeschränkter Funktion und 2 fehlgeschlagene Eingriffe mit größeren Amputationen. Nur in einem Fall kam es zu einer erneuten Infektion.

Schlussfolgerungen Die Rekonstruktion von Knochendefekten mit vaskularisierten Fibula-Transplantaten bei schweren Knocheninfektionen ist eine effektive Behandlungsoption. Sie erfordert jedoch ein versiertes multidisziplinäres Team zur Beherrschung der hohen Komplikationsrate. In unserer Studie traten Komplikationen in erster Linie bei Patienten auf, die gemäß der Cierny-Mader-Klassifikation als Wirte vom Typ B definiert wurden $(p<0,05)$, und bei Patienten mit einer Diskrepanz des Durchmessers zwischen Fibula und rekonstruiertem Knochen, z. B. Tibia und Femur $(p<0,005)$. Des Weiteren erwiesen sich Stressfrakturen als prognostische Indikationen für ein allgemeines Behandlungsversagen $(p<0,05)$.

\section{ABSTRACT}

Purpose This study is a retrospective analysis of our experience in microsurgical bone transfers for complex limb reconstructions. The aim of this study is to evaluate reliability of the vascularized fibula technique: infection recurrence, hypertrophy, time to bone union, complications, and time to healing in severe osteomyelitis (Cierny-Mader III and IV) cases over a 38 to 93 month follow-up.

Patients and Methods From March 2010 until December 2015, 18 patients' limbs ( 6 females and 12 males; mean age 48.7 years) were reconstructed with 10 free fibula flaps, 5 pedicled fibula flaps, 3 peroneus brevis osteomuscular flaps. We reconstructed 2 radiuses, 2 ulnae, 4 femurs, 4 tibiae, 1 acetabulum and 3 fibular malleoli. 
Results We considered as successful results all cases where patients had successful functional bone reconstruction with no recurrence of infection during the follow up (mean time 63.6 months). We obtained 14 complete functional reconstructions, 2 limb salvages with impaired function, and 2 failures which underwent major amputations. In only one case there was an infection recurrence.

Conclusions The bone defect reconstruction with vascularized fibula grafts in severe bone infections is an effective option, but requires a well trained multidisciplinary team to manage the high rate of complications. Complications, in our series, were demonstrated to be significantly associated to patients defined as B-hosts according to Cierny-Mader's classification $(P<0.05)$, and caliber discrepancy between fibula and reconstructed bones such as Tibia and Femur $(P<0.005)$. Furthermore, stress fractures in the grafted fibulae were prognostic indicators for overall treatment failure $(P<0.05)$.

\section{Introduction}

Taylor and co-workers performed the first microvascular bone transfer using a vascularized osteomuscular fibula to obtain the reconstruction of a post-traumatic defect of the tibia in 1975 [1]. At the beginning surgeons harvested fibula flaps with a posterior approach with primary indications for reconstructions of massive bone defects of the limbs. First transfers of the fibula were performed without the harvest of skin paddle, Chen and Yan described for the first time an osteocutaneous fibula flap in 1983 [2]. Gilbert suggested using a lateral approach for harvesting the bone flap and it was useful to realize this new kind of multi-tissue flap. Lateral approach is easier and allows for visualization of the cutaneous branches of the peroneal artery [3]. Hidalgo contributed to the improving of the number of indications using an osteotomized fibula to perform the first lower-jaw reconstruction in 1989 [4].

Posttraumatic bone and soft tissue defects are frequently the consequence of high-energy trauma. Different strategies have been described in the treatment of severe open lower extremity fractures: early aggressive and repeated débridement of dead tissues, fracture stabilization (usually with external fixation), early soft-tissue coverage with local muscle flaps or free muscle transfers [5] and staged skeletal reconstruction [6]. For bone reconstruction, different techniques have been described: direct non vascularized cancellous bone grafts [7], cancellous Papineau or Masquelet style grafting [8], the llizarov bone transport [9], and vascularized bone grafts [10]. Gustilo's open fractures grades IIIB and IIIC with extensive soft-tissue involvement and bony defects often need free soft-tissue coverage and vascularized bone graft to achieve a functional result. Vascularized bone grafting has been recommended for bone defects larger than 6-8 cm [11]. Vascularized bone flaps have good qualities: good mechanical strength, infection resistance, rapid remodelling and hypertrophy [12].

The introduction of vascularised fibula flap has improved results for nonunion associated with bone deficiency and bone infections [13].

Vascularized fibula graft aptitude to hypertrophy allows mechanical performance of lower-limb reconstructions and mechanical loading $[13,14]$. Clinical studies have demonstrated the importance of vascularized grafts regarding the bone union and the resistance to infection [15].

Free vascularized fibula grafts are today established surgical options for reconstruction of massive bone defects after bone tumour resections and radical bone resections in osteomyelitis [16, 17]. An essential instrument for the treatment of massive infected bone and near soft tissue involved is the Cierny-Mader staging system. Cierny-Mader staging system gives a clinical stage of osteomyelitis, setting progressive stages of the disease with prognostic indicator and selecting the surgical approach [18].

\section{Patients and methods}

From March 2010 through December 2015, 18 cases of vascularized fibular grafting have been performed at our institution ( $\triangleright$ Table 1). All discussed cases were posttraumatic bone infections. All patients were retrospectively studied ( 12 men and 6 women) mean age 48.7 years (range 27 to 67 years). The average duration from the first injury to our surgery was 50 months (range, 1 to 480 months). Our treatment selection follows Cierny/Mader staging system. From the patient evaluation to the follow-up, all steps follow the treatment algorithm for adult chronic osteomyelitis [18]. During surgical treatment soft tissues are resected reaching well perfused margins, all infected and dead bone is excised until exposed surfaces bleed in a uniform, Haversian (cortical), or sinusoidal (cancellous) pattern (the paprika sign). All foreign bodies and surgical implants are removed [18].

Ten patients needed internal stabilization and therefore have been treated with two-stage reconstructions: surgical implants removal, radical bone resection and temporary positioning of antibiotic loaded cement hardware spacer and systemic antibiotic therapy. When infection ( $\triangleright$ Table 2 ) signs were negative, patients underwent bone reconstruction. Eight patients have been treated in one stage reconstruction: implants removal bone resection and bone reconstruction in a single time. All patients with Cierny-Mader (CM) IV osteomyelitis received vascularized bone graft for complex limb reconstruction with long segmental bone defects ( $\triangleright$ Fig. 1). The recipient sites were tibia in 5 cases, femur in 4 cases, radius in 2 cases, ulna in 2 cases, acetabulum in 1 case, and the Ist Metatarsal in 1 case, where an osteocutaneous fibula double "Clock Flap" was performed [19]. Three cases with fibular CM III received osteomuscular peroneus brevis pedicled flaps covered with skin grafts [20].

In CM IV osteomyelitis, the average length of bony resection ( Fig. 2) was $11.7 \mathrm{~cm}$ (range 2.8 to $18.5 \mathrm{~cm}$ ) and the average length of the flaps was $15 \mathrm{~cm}$ (range, 2.8 to $27 \mathrm{~cm}$ ). Seven fibulae were pedicled, nine fibulae were revascularized. All free fibula flaps were harvested contralateral respect to recipient site. In CM IV, fibula flaps were secured with plates and screws in four cases (all upper limb reconstructions), with Ilizarov external fixators in 5 cases and with monoaxial external fixators in 4 cases. The first metatarsal was 


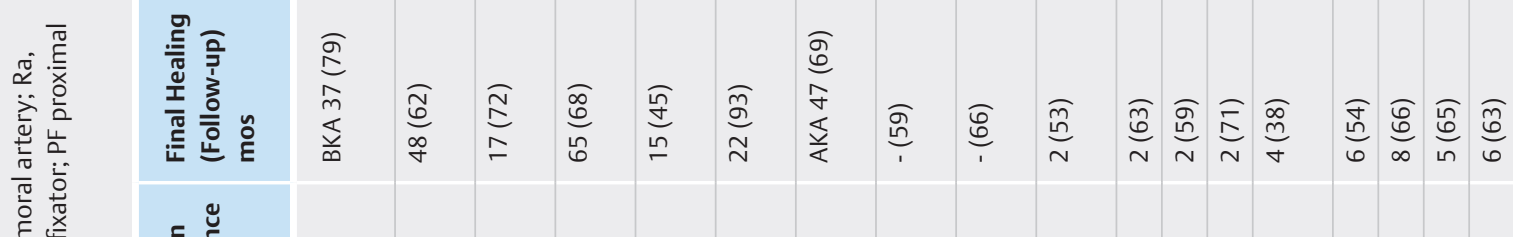

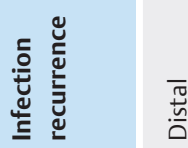

高产

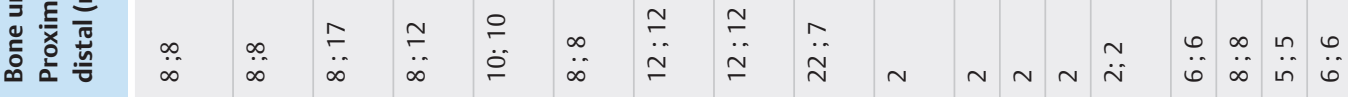

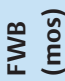

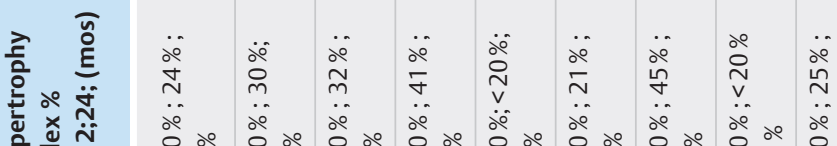

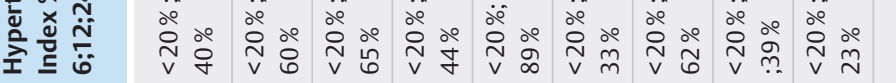

0 .

ज地

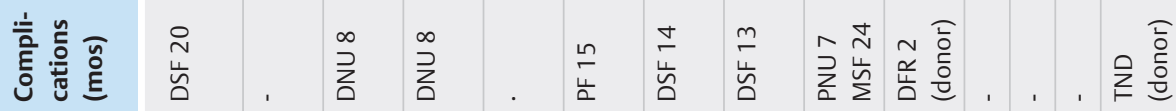

剀.

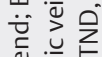

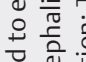

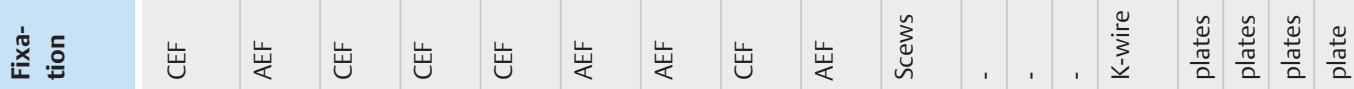

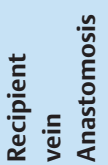

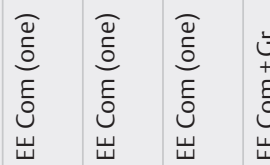

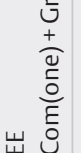

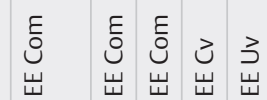

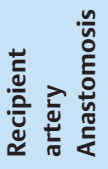

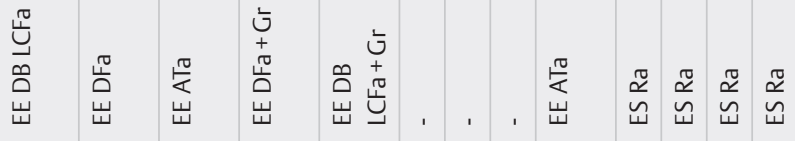

营

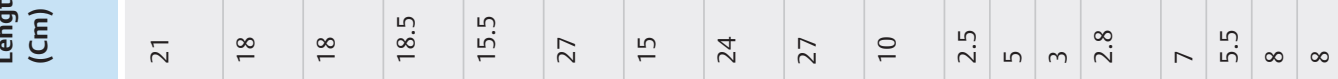

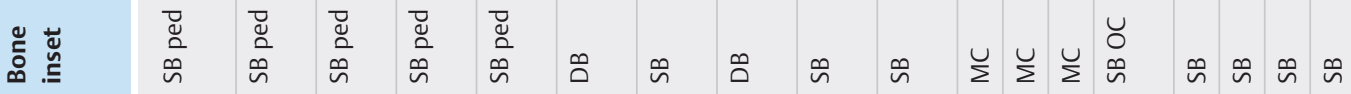

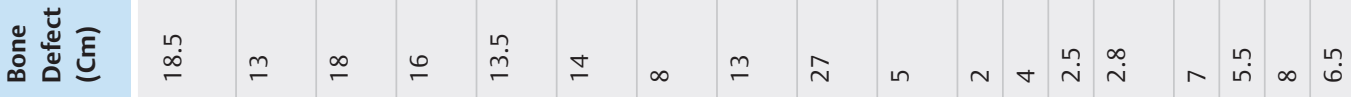

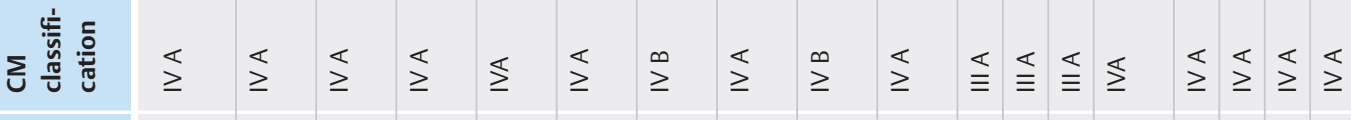

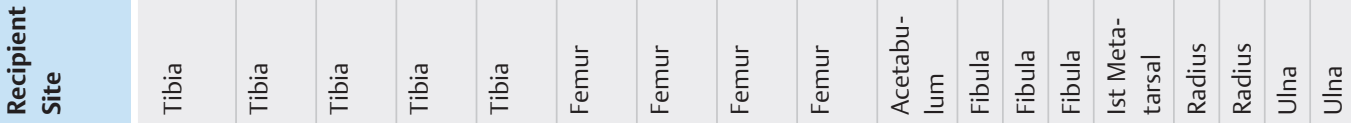
空离 要焉

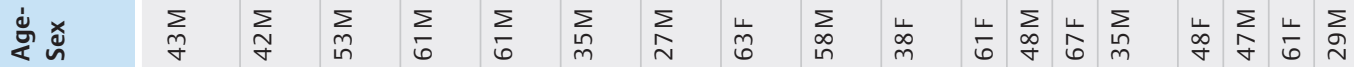

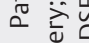


- Table 2 Isolated Microorganisms: MRSE, methicillin resistant staphylococcus epidermidis; PA, pseudomonas aeruginosa; SM, stenotrophomonas maltophilia; EC, enterobacter cloacae; AB, acinetobacter baumannii; EF, enterobacter faecalis; SAu, staphylococcus aureus; SAg, staphylococcus agalactiae; SF, staphylococcus felis; SC, staphylococcus capitis ssp ureolyticus; MRSA, methicillin resistant staphylococcus aureus; MRSC, methicillin resistant staphylococcus capitis; MRSH, methicillin resistant staphylococcus hominis; PP, pseudomonas putida.

\begin{tabular}{|c|c|c|c|c|c|c|c|c|c|c|c|c|c|c|c|}
\hline Case & Age-Sex & MRSE & MSSA & MRSA & MRSC & MRSH & SAg & SF & SC & AB & PA & SM & EF & EC & PP \\
\hline 1 & $43 \mathrm{M}$ & & + & & & & & & & & + & & & & \\
\hline 2 & $42 \mathrm{M}$ & & & & & & & & & & & + & & + & \\
\hline 3 & $53 \mathrm{M}$ & + & & & + & & & & & & & + & & & \\
\hline 4 & $61 \mathrm{M}$ & & + & & + & & & & & & & & & & \\
\hline 5 & $61 \mathrm{M}$ & + & & & & & & & & & & & & & \\
\hline 6 & $35 \mathrm{M}$ & + & & & & & & & & & & & & & \\
\hline 7 & $27 \mathrm{M}$ & & & & & & & & + & & & & & & \\
\hline 8 & $63 F$ & & + & & & & & & & + & & & + & & \\
\hline 9 & $58 \mathrm{M}$ & + & + & & & + & & & & + & + & & & & \\
\hline 10 & $38 \mathrm{~F}$ & + & & & & & & & & & & & + & & \\
\hline 11 & $61 \mathrm{~F}$ & & + & & & & & & & + & & & + & & \\
\hline 12 & $48 \mathrm{M}$ & + & & & & & + & + & & & & & & & \\
\hline 13 & $67 \mathrm{~F}$ & + & & & & & & & & & & & & & \\
\hline 14 & $35 \mathrm{M}$ & & & & & & & & & & & + & & & + \\
\hline 15 & $48 \mathrm{~F}$ & + & & & & & & & & & & & & & \\
\hline 16 & $47 \mathrm{M}$ & & & + & & & & & & & + & & & & \\
\hline 17 & $61 \mathrm{~F}$ & & & & + & & & & & & & & & & \\
\hline 18 & $29 \mathrm{M}$ & & + & & & & & & & & & & & & \\
\hline
\end{tabular}
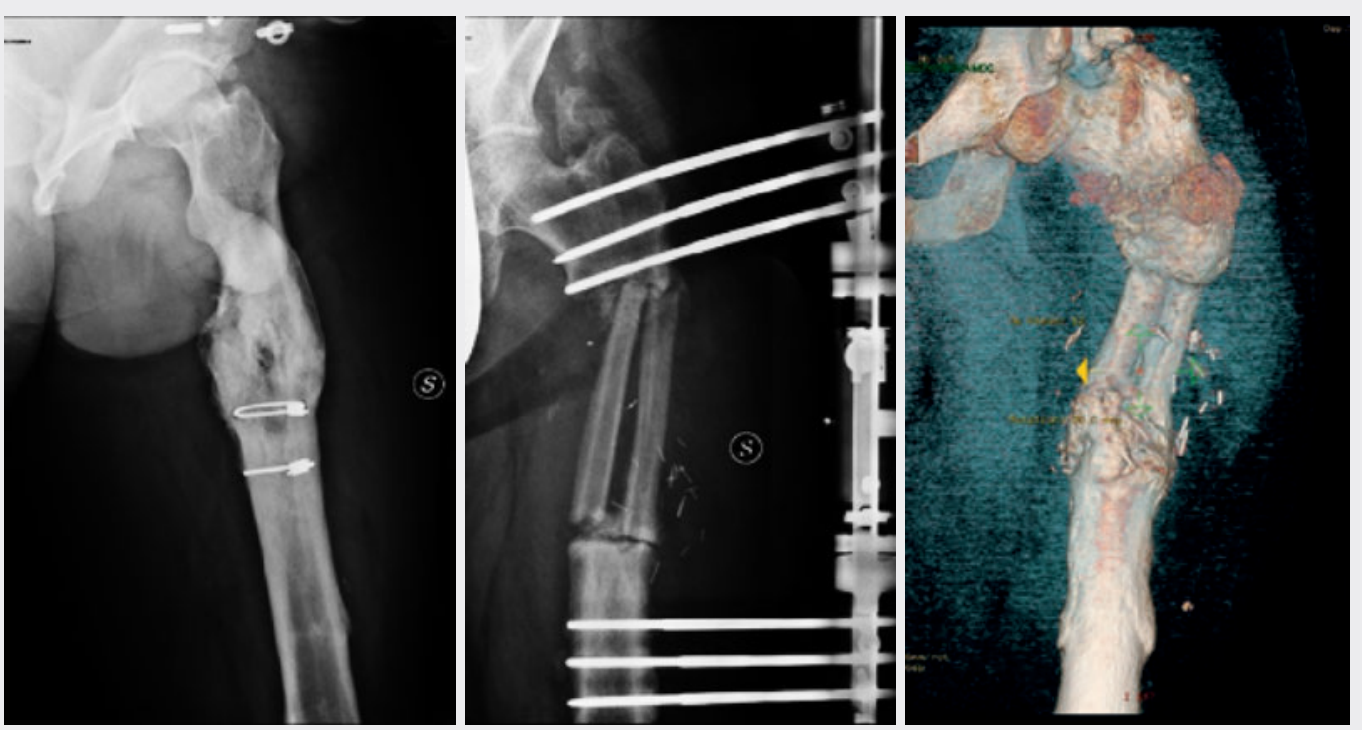

\Fig. 1 Patient number 6 ( $\triangleright$ Table 1). From the left: femur osteomyelitis CM IV; reconstruction with free fibula flap double-barrel three months post-operative X-Ray; one year after surgery 3D CT reconstruction.

stabilized with a K-wire, while the single case of acetabular reconstruction was secured with screws. Three cases of peroneus brevis osteomuscular flap had pressfit insetting of the bony tissue, needing no fixation hardware.
After surgery all patients underwent a strict follow up evaluating laboratory works (ESR/CPR), radiological imaging, wound surveillance. The mean follow-up period was 63.6 months (range, 38 to 93 months). Hypertrophy of transferred fibula was evaluated in lower limb reconstructions except for acetabulum reconstruc- 


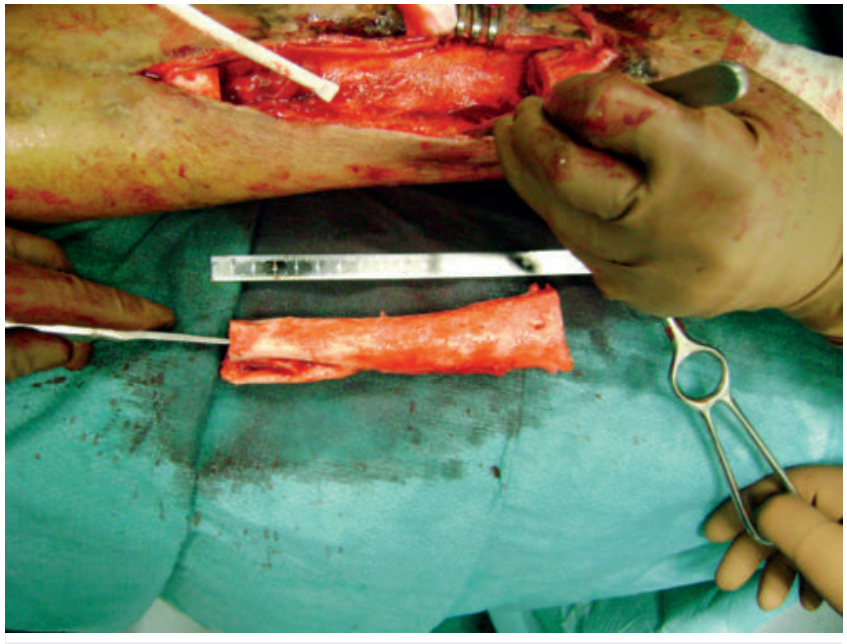

- Fig. 2 Radical tibial resection in case number 1 ( $\bullet$ Table 1$)$.

tion and CM III cases treated with peroneus brevis osteomuscular flaps. Fibula flap hypertrophy was calculated using the graft hypertrophy index (HI) of De Boer and Wood: evaluations were at 6, 12, 24 months with radiogram controls.

G1 = mean original anteroposterior and lateral width of the fibular graft, R1 = mean original anteroposterior and lateral width of the recipient bone, G2 = mean anteroposterior and lateral width of the fibular graft at follow-up, and R2 = mean anteroposterior and lateral width of the recipient bone at follow-up [21].

Fibular graft width was measured at the midpoint of the graft. In two cases where the grafts were in double barrel fashion, the graft width was taken as the mean width of the two struts. The recipient bone width was the mean width of the bone proximal and distal to the fibular graft at fixed points away from the graft host junctions [21].

\section{Results}

\section{Success rate}

We analysed singularly different aspects of the treatment. We considered successful results all cases where patients had successful functional bone reconstructions with no recurrence of infection during the follow up (mean time 30 months). We obtained 14 fully functional reconstructions and in only one case there was an infection recurrence.

\section{Infection recurrence}

One single ipsilateral fibula used for tibial reconstruction (Patient 1 in $>$ Table 1) had a recurrence of infection 30 months after reconstruction. Recurrence was diagnosed by clinical inspection (pus secretion from fistula) 30 months after reconstruction, and confirmed by MRI, at the distal docking site of the fibula graft.

\section{Bone union}

Bone union was eventually assessed in 15 out of 18 reconstructions evaluated on XR records ( $\triangleright$ Fig. $\mathbf{3}$ ). In 13 patients, bone union was uncomplicated and achieved primarily: Out of 28 total docking sites for 14 treated long bones, 25 healed primarily after a mean of
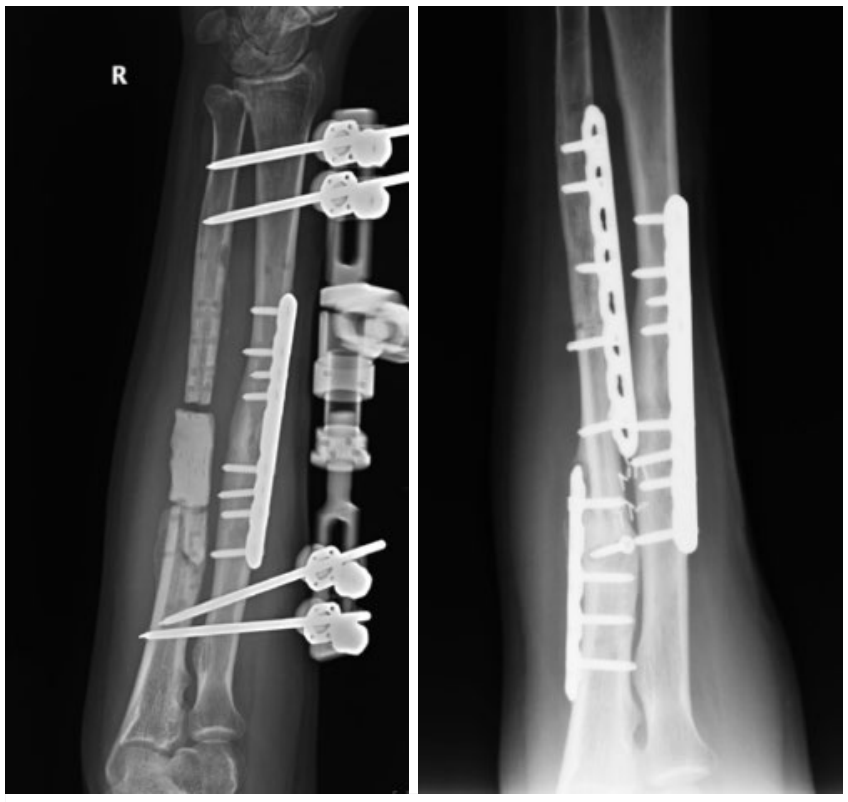

Fig. 3 Two stage ulna reconstruction in case number 18 ( $\triangleright$ Table 1). From the left: antibiotic loaded spacer; bone union six months post free fibula flap reconstruction.

7.7 months (average 8.4 for lower limbs, 6.25 for upper limbs). All three patients with CM III and treated by monocortical reconstruction showed bone union 2 months postoperatively. Three patients with segmental bone reconstructions for CM IV disease showed non-union: one at the proximal end and two at the distal end of the graft at the time of consolidation of the opposite docking site. All patients with non-union required secondary surgery and 2 out of 3 achieved healing after 12 and 17 months from the first treatment.

\section{Hypertrophy}

Measurement of hypertrophy has been possible in 9 patients treated by segmental long bone resection. We excluded upper limb reconstructions, the acetabular and metatarsal reconstructions and peroneus brevis osteomuscular flaps with a monocortical fibula segment. The range of observed hypertrophy was from less than $20 \%$ up to $89 \%$. Index value of more than $20 \%$ was confirmed as graft hypertrophy. In all cases first evaluations six months after surgery had no significant hypertrophy (value $<20 \%$ ). Hypertrophic changes occurred in all the transferred grafts ( $\triangleright$ Fig. 4 ). In one case of femur reconstruction, hypertrophy index decreased during the second follow up year and lead to one of the reconstructive failures in this series. In one case of tibia reconstruction follow up was inferior to twenty four months. There was no significant difference in fracture rate between single barrel and double barrel grafts, but the number of cases is insufficient to draw any conclusions.

\section{Stress fracture}

We registered 5 fractures after full weight bearing in lower limb segmental reconstructions. We diagnosed stress fractures as a clear fracture line seen on plain radiographs accompanied with symptoms of localised pain and tenderness ( $\bullet$ Fig. 5 ). One case of femur reconstruction had an overload fracture at the proximal end of the graft after seven months with full weight bearing. 


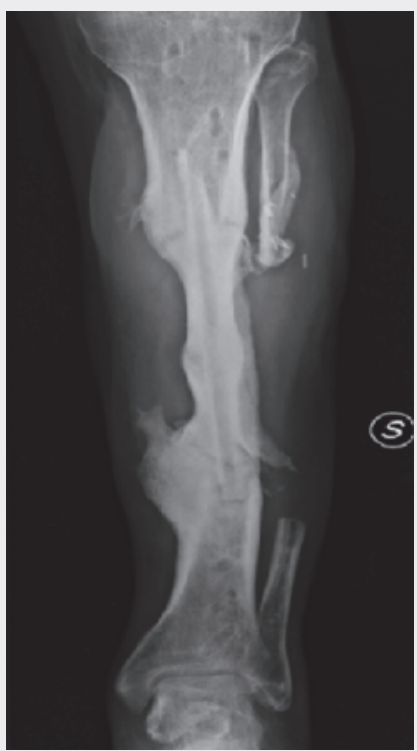

-Fig. 4 Patient number 2 ( $\triangleright$ Table 1 ): pedicled fibula flap for tibial reconstruction: hypertrophy 15 months after surgery.

Two femur reconstructions and one tibia reconstruction had stress fractures at distal end of the graft respectively after one, two and twelve months with full weight bearing. The longest reconstructed femoral segment fractured in its middle third two months after consolidation of the proximal docking site non-union. The fractured evolved into a non-painful hypertrophic non-union and the patient refused any further treatment. All other fractured patients required secondary surgery, and final healing was obtained in only one case after a 7-month secondary treatment with an external fixator. The remaining 3 fractures hesitated in 2 amputations and one chronic limb impairment (walking with crunches and a custom splint).

One of the fractures occurred at the site of infection recurrence and happened after 8 months of full weight bearing. The diagnosis of infection was only assessed 30 months after the surgical reconstruction when a fistula with purulent secretion showed up and MRI confirmed severe endostal inflammation. No prior clinical evidence was present.

\section{Donor site}

One patient showed flexor retraction of $1^{\text {st }}$ and $2^{\text {nd }}$ toe, requiring surgical management (tenotomy). Another patient had a transitory partial sensitive palsy of the Tibial nerve (dysesthesia), spontaneously improved and eventually disappeared 3 months after surgery.

\section{Time to full weight bearing (FWB)}

We considered time to full weight bearing in lower limb reconstructions the time until the patient could walk without crutches (in some cases with a splint). In all CM IV cases, except for the $27-\mathrm{cm}$ femoral reconstruction, time to full weight bearing ranged from 4 to 15 months. All other cases healed and were allowed complete weight bearing at some time. Stress fractures occurred 1 month

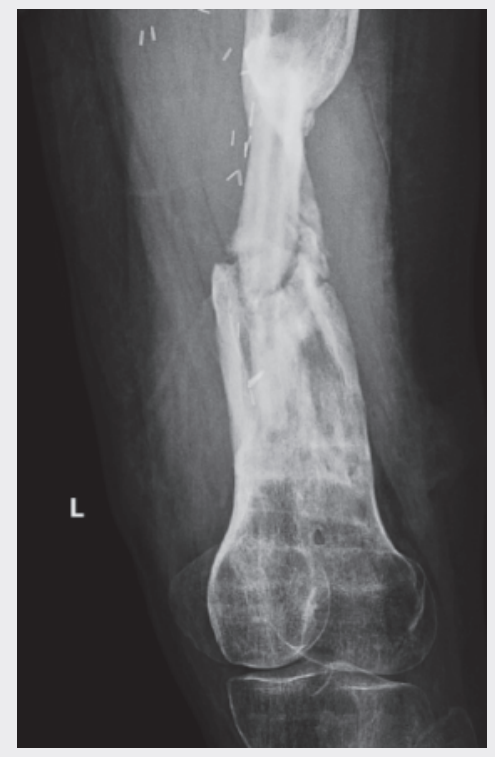

- Fig. 5 Patient number 7 ( $\triangleright$ Table 1): 14 months after surgery distal stress fracture.

after FWB in the two non infected patients, and 8 months after FWB in the infection recurrence. In CM III cases, patients had full weight bearing 2 months after surgery.

\section{Discussion}

\section{Bony union}

We considered different bone union timings due to different bone reconstructions between CM IV patients and CM III patients. All CM IV patients received segmental fibula bone transfers with external fixation and had longer time to reach bone union respect to CM III patients treated with peroneus brevis osteomuscular flaps. Time to bony union in CM IV cases also needs to be distinguished between upper limb and lower limb reconstructions. We evaluated more time to bone union in lower limb femur reconstructions: primary bone union after an overall average time of 11.6 months. We considered femur reconstruction the most challenging limb bony reconstruction due to the long bone defects, recipient bone diameter and revascularization of the bone graft used. In case number 9 ( $\triangleright$ Table 1) we observed non-union in the proximal head of a single barrel free fibula graft after seven months. We think it could be related to the long bone gap and the use of a long fibula single barrel flap $(27 \mathrm{~cm})$ : original reconstruction project was a double fibula flap reconstruction, but general conditions of the patient did not allow such an aggressive procedure. Secondary surgery was necessary to perform a proximal osteotomy and deformity correction with a circular external fixator. Tibial reconstructions with pedicled fibula transfers had average time of primarily bone union at 8 months. Patients number 3 and 4 in $>$ Table 1 had distal bony non-union both at 8 months. They received secondary surgery with distal ends of the grafts curettage, osteotomies and bone stabilizations with circular external fixators. Overall bony union in tibial 
reconstructions was achieved at 9.7 months average time. In CM IV upper limb reconstructions time to bony union was primarily obtained in 6.25 months average time and no complications were observed. In all CM III cases we used peroneus brevis osteomuscular flaps filling cortical fibular gap in lateral malleolus region, we found a good radiographic consolidation after 2 months. External fixation was unnecessary because we fixed the bony component of the flaps in a press-fit fashion.

In our case series, nonunions had no statistical significance in predicting final failure of the treatment.

\section{Hypertrophy}

Vascularized bone grafts, and in particular fibula flaps, have the capability to achieve a good degree of hypertrophy. Factors which influence this modification are mechanical loading, age, and the periosteal vascularization [22, 23]. In literature studies have calculated measurement of hypertrophy. Some authors consider only its presence or absence $[22,24]$. Some authors tried to find a method for evaluation of hypertrophy [25]. We considered hypertrophy only in CM IV lower limb reconstructions due to the presence of mechanical load and we found that the fibula hypertrophied in all cases of lower limb reconstruction where there was mechanical stress through the recipient bone. All patients at six months after surgery had no significant hypertrophy (all HI values $<20 \%$ ). We consider it was related to the presence of external fixation with a partial load bearing. Hypertrophy increased after external fixator removal and in all patients $\mathrm{HI}$ values were $>\mathbf{2 0} \%$ at twelve months controls.. Patients evaluated two years after surgery had more significant graft hypertrophy. In Case number 11 hypertrophy was minimal because the patient has not yet reached full weight bearing at the time of publishing. Hypertrophy was not calculated in patient number 16 because the presence of the prosthesis did not allow correct XR evaluation. Experiments conducted by Fujimaki et al. on puppies reported that hypertrophy did not grow more than the width of the recipient bone [22]. They suggested that normal bone healing by callus formation and fibular hypertrophy are different processes. They believed that the size of the recipient bone was an influential factor in the hypertrophy. We measured bone diameters to calculate $\mathrm{HI}$ at the middle length of the graft and several $\mathrm{cm}$ far to the osteotomies at the recipient bone, as other authors [14]. In their studies, De Boer et al. suggested three different entities of hypertrophy: 'periosteal', 'endosteal' and a mixture of the two [26]. Panuel et al. conduced imaging studies evaluating the vascularised fibula flaps in children to demonstrate the involvement of the periosteum in the hypertrophy process [27]. In their studies they showed a model of hypertrophy even without weight-bearing and considered periosteal reaction consequence of little traumatisms of the periosteum during the harvesting of the grafts.

\section{Stress fracture}

We only assessed stress fractures in CM IV lower limb reconstructions. Our stress fracture rate, 5 on 9 cases (only lower limb long bone reconstructions are considered) is comparable with other studies [13, 25, 28]. All cases of stress fracture were symptomatic and were diagnosed with XR. Stress fractures occurred after an average time of 3.75 months of full weight bearing, and in case number 6 the patient had an overload fracture occurred using a gym leg press machine for physical exercise seven months after free full weight bearing: it was a proximal callus mobilization and we may not be consider this complication as a proper "stress fracture". Three other fractures occurred at the distal third of the grafts and one in the middle third. There was no clinical evidence of infection recurrence at fracture level at the time of presentation of the complication, neither in the case later proved to be a recurrence of the osteomyelitis. In all cases corrective surgery was necessary using external fixation to support the fibula until sufficient XR evidence of callus allowing weight bearing. Previous studies considered double-barrelling of the fibula a good technique to reduce the incidence of stress fractures [29]. In our case series one of the two double barrel fibula had a stress fracture, and we consider it a consequence of the particular double barrelling in a "reverse Y shape" to reconstruct the distal femur metaphysis.

In this series, stress fractures are significantly associated to treatment failure $(P<0.05)$

\section{Full weight bearing}

Time to full weight bearing is an important index of healing. Patients reach full weight bearing when external fixators have been removed and they have no particular pain during walking. All CM III reconstructions had full weight bearing after two months because stability was not compromised by bone resections and bone reconstructions only contributed to the reinforcement of lateral malleolus. In CM IV lower limb reconstructions, 7 patients reached full weight bearing and had no functional limitations, while two went back to walking without crutches. During the external fixation time they progressively increased mechanical load with external fixation stability and protection.

\section{Bone fixation}

In septic bone reconstructions, external bone fixation has an important role in successful rate of treatments. Minimal bone surface contact with fixation hardware reduces infection recurrences. We used external fixation tools in all CM IV lower limb reconstructions. During external fixator application surgeons have to protect the vascular pedicle of the flap to prevent reconstruction failure. A vascularised bone graft reconstruction reaches more rapid bone union if there is rigid fixation of the bone ends [25]. One of the critical point is the fibula insetting maintaining the alignment with the recipient bone and preserving vascular pedicles. We used several fixators. The use of the modified Ilizarov frame is helpful. Collaboration between orthopaedics and plastic surgeons is fundamental. An essential key point is the half-ring fixator construction: we can remove the anterior half of the frame to facilitate the fibula transfer and allowing free access to the recipient vessels, for example, the anterior tibial artery in the lower limb. At the end of these operations the half ring is reapplied to obtain a definitive stabilisation. Compression of the bone ends is obtained with a gradual tightening of the frame and stimulates healing. Axial load is transmitted symmetrically and patients can start weight-bearing after few weeks compatibly with pain reduction. Minami demonstrated that grafts which had been properly aligned, had less fractures [10]. 


\section{Donor site morbidity}

We registered minimal donor site morbidity (two minor complications) following the lateral harvesting surgical way. Motor weakness sensory deficit and flexion contracture of the toes are rare [30]. Knee and ankle donor sites maintain their stability due to preservation of the six proximal and distal centimetres of the fibula at the donor sites.

\section{Success rate and infection recurrence}

We considered successful results all cases where patients had successful functional bone healing with no recurrence of infection during the follow up (mean time 63.7 months). We therefore obtained 14 fully functional reconstructions, one BKA, one AKA, and two salvaged but chronically impaired limbs. In only one case there was an infection recurrence. Infection recurrence is the most important complication in the treatment of chronic osteomyelitis: it means that treatment has not been radical. In our cases, patient number two had an infection recurrence 30 months after reconstruction at the distal end of the graft. We have to consider that these patients have faced numerous hospitalizations before coming to our center: the average duration from injury to our surgery was 50 months (range, 1 to 480 months). Often these patients after previous treatments had been considered healed and they have showed signs of recurrence several years later. When infection recurrence occurs after multiple surgical treatments, the patient's compliance becomes an important factor in therapeutic decisions. In these complex cases it is possible that they may refuse surgery or ask for amputation.

In our analysis, in addition to stress fractures - which we already discussed - also patients defined as B-hosts in Cierny-Mader's Classification are significantly related to treatment failure $(\mathrm{p}<0.05)$.

There is no significant statistical evidence of a major overall complication rate in lower limbs or in weight-bearing segments as it might seem reasonable. Our data instead support a significant role in the calibre discrepancy between the reconstructed bone and the fibula: when present it is associated to a higher incidence of complications in the recipient site $(\mathrm{P}<0.005)$.

\section{CONCLUSIONS}

Today, over 90 percent of patients, suffering from chronic osteomyelitis, can expect a successful treatment outcome [18]. Cierny defined a successful treatment as "an infection-free, functional reconstruction at the 2-year follow-up" [18]. Reconstructions with vital autologous tissues are the gold standard after infected bone and soft tissue removal. These reconstructions have multiple functions: mechanical function restoring bone continuity, protection and coverage of vital structures with soft tissues and therapeutic function because blood flow through the flaps increases the delivery of the antibiotic drugs in the debrided and reconstructed area. Vascularized fibula grafts are one of the main options available to surgeons for bone defect reconstructions. This is a very complex surgical field, and the incidence of complications in these procedures is extremely high: 9 cases out of 18 showed some kind of complication during the treatment.
On the other hand, an experienced multidisciplinary team can face complications and obtain an overall satisfying healing rate, which in this series was of 14 cases out of 18 total treatments.

The main negative prognostic indicators are Host-B patients according to Cierny and Mader's classification, and the need to reconstruct thick bones such as Tibia and Femur. When bone defects are short enough, planning a double-barrel reconstruction may help minimize the risk of complications, and surgery on B-hosts should be thoroughly considered.

The diagnosis of a stress fracture during the treatment is significantly associated to failure, therefore patients should be made aware of this data and the opportunity of choosing an amputation may therefore be considered, in order to avoid wasting time on the way to a poor final result.

\section{Conflict of interest}

The authors declare that they have no conflict of interest.

\section{Authors}

\begin{abstract}
Dr. Andrea Antonini
was born in Trieste on October 15 1977.

He graduated in Medicine and Surgery in 2002 and began his residency in Plastic and Reconstructive Surgery in Trieste. During the last two years of training he worked in Dr. Bruno Battiston's Microsurgery Unit in Turin's CTO Hospital, focusing mainly on Hand Surgery, Reconstructive Microsurgery and Peripheral Nerve Surgery. After Specialization, Dr. Antonini worked in the Plastic Surgery Unit in Pietra Ligure, Savona, from 2007 to 2009. In 2010 he moved to the Bone Infection Unit of the same Hospital where he is still working today as a Reconstructive Microsurgeon of the Limbs.

Dr. Antonini is also a member of the Board of the Italian Society for Microsurgery since 2013, and a proud founder, promoter, tutor and teacher in many Microsurgery Courses around Italy and abroad.
\end{abstract}

\section{References}

[1] Taylor GI, Miller GD, Ham F]. The free vascularized bone graft. A clinica extension of microvascular techniques. Plast Reconstr Surg 1975; 55(May (5)): 533-44

[2] Chen ZW, Yan W. The study and clinical application of the osteocutaneous flap of fibula. Microsurgery 1983; 4(1): 11-6

[3] Gilbert A. Free vascularized bone grafts. Int Surg 1981; 66(Jan-Mar(1)): 27-31

[4] Hidalgo DA. Fibula free flap: a new method of mandible reconstruction. Plast Reconstr Surg 1989; 84(Jul (1)): 71-9

[5] Cierny G 3 rd, Byrd HS, Jones RE. Primary versus delayed soft tissue coverage for severe open tibial fractures. A comparison of results. Clin Orthop Relat Res 1983; 178: 54-63 
[6] Byrd HS, Spicer TE, Cierney G 3 rd. Management of open tibial fractures. Plast Reconstr Surg 1985; 76(Nov (5)) :719-30

[7] Christian EP, Bosse MJ, Robb G. Reconstruction of large diaphyseal defects, without free fibular transfer, in Grade-IIIB tibial fractures. J Bone Joint Surg Am 1989; 71(Aug (7)): 994-1004

[8] Green SA, Dlabal TA. The open bone graft for septic nonunion. Clin Orthop Relat Res 1983; 180: 117-24

[9] Dagher F, Roukoz S. Compound tibial fractures with bone loss treated by the Ilizarov technique. J Bone Joint Surg Br 1991; 73(Mar (2)): 316-21

[10] Minami A, Kasashima T, Iwasaki $\mathrm{N}$ et al. Vascularised fibular grafts. An experience of 102 patients. J Bone Joint Surg $\mathrm{Br} 2000$; 82(Sep (7)): $1022-5$

[11] Taylor GI. The current status of free vascularized bone grafts. Clin Plast Surg 1983; 10(Jan (1)): 185-209

[12] Lau RS, Leung PC. Bone graft viability in vascularized bone graft transfer. Br J Radiol 1982; 55(May (653)): 325-9

[13] Yajima H, Tamai S, Mizumoto $S$ et al. Vascularised fibular grafts for reconstruction of the femur. J Bone Joint Surg Br 1993; 75(Jan (1)): $123-8$

[14] Lazar E, Rosenthal DI, Jupiter J. Free vascularized fibular grafts: radiographic evidence of remodeling and hypertrophy. AJR Am J Roentgenol 1993; 161(Sep (3)): 613-5

[15] Wood MB, Cooney WP 3 rd, Irons GB Jr. Skeletal reconstruction by vascularized bone transfer: indications and results. Mayo Clin Proc 1985; 60(Nov (11)): 729-34

[16] Ihara K, Doi K, Yamamoto M, et al. Free vascularized fibular grafts for large bone defects in the extremities after tumor excision. J Reconstr Microsurg 1998; 14(Aug (6)): 371-6

[17] Muramatsu K, Ihara K, Shigetomi M et al. Femoral reconstruction by single, folded or double free vascularised fibular grafts. Br J Plast Surg 2004; 57(Sep (6)): 550-5

[18] Cierny G 3 rd. Surgical treatment of osteomyelitis. Plast Reconstr Surg 2011; 127(Jan (Suppl 1)): 190-204

[19] Antonini A, Rossello C, Salomone C et al. The peroneus brevis flap in the treatment of bone infections of the lower limb. Injury 48: 76-79

[20] Antonini A, Rossello C, Salomone C et al. The Propeller Concept Applied to Free Flaps and the Proposal of a "Clock Flap" Nomenclature. J Reconstr Microsurg: 33: 48-52

[21] El-Gammal TA, El-Sayed A, Kotb MM. Hypertrophy after free vascularized fibular transfer to the lower limb. Microsurgery 2002; 22(8): 367-70

[22] Fujimaki A, Suda H. Experimental study and clinical observations on hypertrophy of vascularized bone grafts. Microsurgery 1994; 15(10): 726-32

[23] Bos KE, Besselaar PP, vd Eijken LW et al. Failure of hypertrophy in revascularised fibula grafts due to stress protection. Microsurgery 1996; 17(7): 366-70

[24] Low CK, Pho RW, Kour AK et al. Infection of vascularized fibular grafts. Clin Orthop Relat Res 1996; 323: 163-72

[25] de Boer HH, Wood MB, Hermans J. Reconstruction of large skeletal defects by vascularized fibula transfer. Factors that influenced the outcome of union in 62 cases. Int Orthop 1990; 14(2): 121-8

[26] DeBoer HH. Vascularized fibular transfer, Thesis, Leiden, The Netherlands; 1988

[27] Panuel M, Petit P, Jouve JL et al. Imaging of vascularized fibular grafts in large bone reconstruction in skeletally immature patients. Skeletal Radiol 1997; 26(Jul (7)): 404-8

[28] Takami H, Takahashi S, Ando M et al. Vascularized fibular grafts for the reconstruction of segmental tibial bone defects. Arch Orthop Trauma Surg 1997; 116(6-7): 404-7
[29] Yajima H, Tamai S. Twin-barrelled vascularized fibular grafting to the pelvis and lower extremity. Clin Orthop Relat Res 1994; 303: 178-84

[30] Takakura Y, Yajima H, Tanaka Y et al. Treatment of extrinsic flexion deformity of the toes associated with previous removal of a vascularized fibular graft. J Bone Joint Surg Am 2000; 82(Jan (1)): 58-61 